\title{
Metafísica prática em Schopenhauer: compaixão, amor sexual e magia como fenômenos da identidade metafísica da vontade ${ }^{1}$
}

\author{
Praktische Metaphysik bei Schopenhauer: das Mitleid, die \\ Geschlechtsliebe und die Magie als die Phänomene der metaphysichen \\ Identität des Willens
}

\author{
Luan Corrêa da Silva \\ Doutorando em Filosofia pela UFSC \\ E-mail: luanbettiol@gmail.com
}

\begin{abstract}
Resumo: O objetivo deste artigo é o de investigar a passagem que afirma a possibilidade de manifestações empíricas da identidade metafísica da vontade como meio pelo qual é possível vivenciar na realidade do mundo efetivo (Wirklichkeit) o nexo volitivo fundamental, o fio condutor das aparências; ou em outros termos: compaixão, amor sexual e magia são a "metafísica prática". Se pela simpatia experienciamos efetivamente o nosso enraizamento no mundo, então esta conexão não pode ser aquela oferecida por qualquer clarividência (Besonnenheit) ou ciência, mas arremessa-nos sem cerimônia em um labirinto obscuro, cujas representações confusas são desprovidas de coerência causal ou lógica. Nestes raros momentos estamos diante de uma mística prática, tal como propõe Schopenhauer.
\end{abstract}

Palavras-chave: Simpatia; Metafísica Prática; Schopenhauer.

Zusammenfassung: Das Ziel dieses Artikels ist zu eine Passage untersuchen, die behauptet, Möglichkeit die Offenbarung der metaphysischen Identität des Willens. Diese Offenbarung ist es, Mittel durch welches es möglich macht, das wesentlich Willensnexus in der Faden der Erscheinungen, im der Realität der wirklichen Welt zu erfahren. Mit anderen Worten: Mitleid, Geschlechtsliebe und Magie sind "praktische Metaphysik". Wenn durch die Sympatie, wir unsere Verwurzelung in der Welt erleben, dann ist diese Verbindung nicht jene durch besonnenheit gegeben, aber Dieses Erlebnis uns in einen dunklen Labyrinth, dessen Vorstellungen von Kausale oder logische Kohärenz frei sind. Im solche seltene Momente, erfahren wir eine Praktische Mystik, wie Schopenhauer vorschlägt.

Stichworte: Sympathie; Praktische Metaphysik; Schopenhauer.

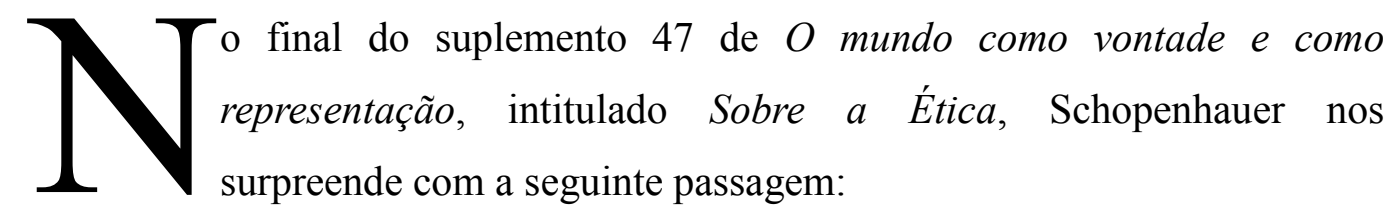

\footnotetext{
${ }^{1}$ Este artigo consiste em uma breve apresentação da tese a ser defendida ao fim do período de meu doutoramento. Faço esta breve apresentação por dois motivos principais: fomentar desde já uma discussão que pode ampliar o horizonte de interpretação da filosofia de Schopenhauer, e também, como consequência, contar com a solidariedade de críticas e sugestões que eventualmente surjam para a composição da versão final do trabalho ainda por vir, através do e-mail luanbettiol@gmail.com . 
Auf dieser metaphysischen Identität des Willens, als des Dinges an sich, bei der zahllosen Vielheit seiner Erscheinungen, beruhen überhaupt drei Phänomene, welche man unter den gemeinsamen Begriff der SYMPATHIE bringen kann: 1) das MITLEID, welches, wie ich dargethan habe, die Basis der Gerechtigkeit und Menschenliebe, caritas, ist; 2) die GESCHLECHTSLIEBE mit eigensinniger Auswahl, amor, welche das Leben der Gattung ist, das seinen Vorrang vor dem der Individuen geltend macht; 3) die MAGIE, zu welcher auch der animalische Magnetismus und die sympathetischen Kuren gehören. Demnach ist SYMPATHIE zu definiren: das empirische Hervortreten der metaphysischen Identität des Willens, durch die physische Vielheit seiner Erscheinungen hindurch, wodurch sich ein Zusammenhang kund giebt, der gänzlich verschieden ist von dem durch die Formen der Erscheinung vermittelten, den wir unter dem Satze vom Grunde begreifen ${ }^{2}$.

A preocupação de Arthur Schopenhauer com esses temas, mesmo quando considerados isoladamente, já chama a atenção de seus leitores, estejam eles habituados ou não com a sua filosofia. De fato, cada um destes temas tem um desenvolvimento próprio, cada qual no seu lugar mais adequado, no interior do corpus filosófico da "metafísica da vontade" schopenhaueriana. Mas o que esta passagem traz de realmente novo é, em primeiro lugar, que eles sejam reunidos no mesmo conceito, simpatia (1); que este conceito seja definido como "a manifestação empírica da identidade metafísica da vontade" (2); que esta manifestação tenha como especificidade revelar empiricamente uma conexão distinta, para além do princípio de razão, isto é, uma identidade não ordinária, da ordem da física (physis), mas metafísica (3) e que esta identidade oculta, metafísica, revele mais do que uma incógnita para além da experiência, mas seja a raiz de cada indivíduo, a sua experiência mais concreta e íntima, vontade.

\footnotetext{
2 "Sobre essa identidade metafísica da vontade, como coisa em si, em meio à pluralidade incontável de suas aparências, baseiam-se três fenômenos, que se pode reunir sob o conceito comum de SIMPATIA: 1) a COMPAIXÃO, que, como expliquei, é a base da justiça e da caridade, caritas; 2) o AMOR SEXUAL, com sua escolha caprichosa, amor, que constitui a vida da espécie que prevalece sobre a dos indivíduos; 3) a MAGIA, à qual se incluem também o magnetismo animal e as curas simpáticas. Por conseguinte, a SIMPATIA pode ser definida como: a manifestação empírica da identidade metafísica da vontade, através da pluralidade física de suas aparências, com o que se dá a conhecer uma conexão, que é completamente diferente daquela conexão intermediada pelas formas da aparência, que concebemos sob o princípio de razão". SCHOPENHAUER, WWV II, Kap. 47, p. 690, tradução e grifos nossos. Chamo a atenção para os usos de "Erscheinung" e "Phänomen" nesta passagem. Aqui, como nas diversas outras passagens, nos valemos da tese de Jair Barboza, para quem o uso destes dois conceitos não é equivalente, em BARBOZA, J. Schopenhauer: 'die Erscheinung', 'das Phänomen'. Revista Voluntas: Estudos sobre Schopenhauer, vol. $5, \quad \mathrm{n}^{\mathrm{o}} \quad 1, \quad$ pp. 03-08. Disponível em: $<$ http://www.revistavoluntas.com.br/uploads/1/8/1/8/18183055/v5-n1-1-2014-art1-barboza jair.pdf $>$.
} Acesso em 15 Jul. 2015. 
Revista Voluntas: Estudos sobre Schopenhauer - Vol. 6, No 1 - $1^{\circ}$ semestre de 2015 - ISSN: 2179-3786 - pp. 28-43.

Estão reunidos compaixão, amor sexual e magia no conceito comum de "simpatia". A razão disso consiste em que estas sejam manifestações empíricas da identidade metafísica da vontade, isto é, que sejam meios pelos quais é possível vivenciar na realidade do mundo efetivo (Wirklichkeit) o nexo volitivo fundamental, o fio condutor das aparências; ou em outros termos: compaixão, amor sexual e magia são a metafísica prática. Isto implica que pela simpatia experienciamos efetivamente o nosso enraizamento no mundo; cuja conexão, todavia, carente de explicação causal, inviabiliza a sua clarividência (Besonnenheit) e, por consequência, qualquer ciência em sentido estrito. Com isso, estamos arremessados em um labirinto obscuro, em que as representações são confusas e as suas explicações mais ainda, mas que todavia evidencia um correlato prático efetivo da metafísica teórica de Schopenhauer. Que a constatação da verdade fundamental da vida tenha origem na experiência íntima do mundo mas, apesar disso, seja indefinível e explicável por conceitos abstratos, isto é o que Schopenhauer chama em determinado momento de "magia da vontade", ensejando uma fortuita associação com o que chamamos de "metafísica prática".

O objeto deste texto é a referida passagem, e o seu propósito é o de explicitar resumidamente a sua tese, a ser compreendida a partir de algumas referências internas ao próprio pensamento de Schopenhauer. Com isso, veremos que esta tese revela uma hipótese de compreensão da filosofia de Schopenhauer pouco explorada por ele, a ser investigada.

\section{A identidade metafísica da vontade}

O tema da identidade pode ser considerado a partir de duas rubricas principais, no interior do pensamento de Schopenhauer: da "identidade causal", desenvolvida na tese sobre A quádrupla raiz do princípio de razão suficiente (1813); e da "identidade da vontade", desenvolvida de forma nuclear no capítulo "Astronomia física" de Sobre a vontade na natureza, ambas, como sabemos, são discutidas amplamente nos volumes de sua obra principal $O$ mundo como vontade e como representação. No primeiro caso, da "identidade causal", reconhecemos como o princípio de causalidade pode assumir aspectos aparentemente desconexos, se considerarmos a variedade com que ela se

\footnotetext{
${ }^{3}$ SCHOPENHAUER, A. Arthur Schopenhauers handschriftlicher Nachlaß. Philosophische Vorlesungen Metaphysik der Natur. In: SCHOPENHAUER, A. Arthur Schopenhauers sämtliche Werke, vol X; hrsg. Von Paul Deussen. Munique: R. Piper, 1913, p. 143.

Metafisica prática em Schopenhauer 


\section{LUAN CORRÊA DA SILVA}

manifesta na variedade dos seres da natureza. A causalidade mostra-se, a partir disso, enquanto mecânica, estímulo e motivo, correspondendo aos reinos inorgânico e orgânico, que tem como grau mais elevado de desenvolvimento o ser humano. Aqui o movimento da ação provocada pelos pensamentos humanos, enquanto resultante dos motivos predominantes, não ocorre com menos necessidade do que a da esfera impelida pelo choque; estão todos reunidos na identidade da causalidade.

Esta identidade, todavia, só pode ser confirmada por uma outra, na medida em que mesmo a essência da efetividade (Wirklichkeit), a causalidade, possui seu fundamento último em um movimento anterior e interior a este, na identidade da vontade. Esta identidade interna, da vontade, aparece como a chave para a compreensão da primeira:

Também ali, onde a causa mais palpável traz consigo o efeito, esse elemento misterioso ainda presente, esse $\mathrm{x}$ ou o efetivamente interno ao evento, o verdadeiro agente, o em si dessa aparição - a qual, afinal, nos é dada apenas como representação e segundo as formas e leis da representação - é essencialmente o mesmo que aquilo que, nas ações de nosso corpo, igualmente dado como intuição e representação, nos é íntima e imediatamente conhecido como vontade ${ }^{4}$.

Desse modo, o cerne de Sobre a vontade na natureza ${ }^{5}$ é o problema da passagem [Übergang] pelo profundo abismo existente entre a aparência e a coisa em si, que, embora barrada pela doutrina kantiana do idealismo transcendental como absolutamente incognoscível, é possibilitada na medida em que não se incorra no equívoco de aplicar a causalidade (em sentido estrito) sobre um domínio inteiramente anterior a ela. Ou seja, aquilo que conhecemos do mundo, portanto como um produto fisiológico de nosso cérebro (imbuído das formas do espaço, tempo e causalidade), e que constitui o conteúdo da aparência - a representação ${ }^{6}$ - não pode sequer ser pensado sem que se suponha uma existência em si mesma, e não simplesmente como objeto para um sujeito. Do contrário, sucumbiríamos ao que Schopenhauer chama de "egoísmo teórico", como é o caso do idealismo absoluto, em que toda realidade do mundo é diluída como um mero "fantasma subjetivo" (WWW II, p. 216). Assim, apenas considerando que a

\footnotetext{
${ }_{5}^{4}$ SCHOPENHAUER, N, p. 150.

${ }^{5}$ Remeto-me à resenha anteriormente publicada da tradução deste escrito, ao qual me remeto com frequência. SILVA, L. C. Sobre a vontade na natureza (Resenha). Tradução, prefácio e notas de Gabriel Valladão Silva. Porto Alegre: L\&PM, 2013, 236p. Revista Voluntas, 2014. Disponível em: http://www.revistavoluntas.com.br/uploads/1/8/1/8/18183055/v4-n2-2-2013-res01luan_correa da silva.pdf Acesso em 15 Jul. 2015.

6 “Todo conhecer é essencialmente um representar" (SCHOPENHAUER, WWV II, p. 216).

Metafísica prática em Schopenhauer
} 
Revista Voluntas: Estudos sobre Schopenhauer - Vol. 6, № 1 - $1^{\circ}$ semestre de 2015 - ISSN: 2179-3786 - pp. 28-43.

diferença nos seja dada na representação é que se torna possível pensar em uma identidade entre vontade e representação.

O conhecimento da identidade entre vontade e representação nos é dado, como sabemos, na consciência de si (Selbstbewusstsein), de forma quase totalmente imediata e, portanto, limitada. Esse conhecimento de si é mediado minimamente pela relação instrínseca de todo conhecimento (sujeito e objeto) e pelo tempo, como figura pura do Princípio de Razão. Ora, se a consciência de si exige que esta se volte para o seu interior, por uma via subterrânea àquela da consciência externa, então não surpreende que Schopenhauer tenha localizado no corpo (Leib) o foco da vontade. Pois, se o mundo nos é conhecido, ele só o pode ser a partir do corpo, do contrário o indivíduo pareceria como que uma "cabeça de anjo alada destituída de corpo"7 . O indivíduo enraíza-se no mundo pela vontade, e por isso ele pode afirmar com convicção: o mundo é meu corpo, ora conhecido enquanto minha representação, ora enquanto minha própria vontade.

Todo ato verdadeiro de sua vontade é simultânea e inevitavelmente também um movimento de seu corpo (...) mas são uma única e mesma coisa, apenas dada de duas maneiras totalmente diferentes, uma vez imediatamente e outra para a intuição do entendimento ${ }^{8}$.

É no corpo, como objetidade da vontade, que encontramos a chave para a compreensão da identidade metafísica, como seu lugar privilegiado, embora este conhecimento seja limitado ao conhecimento do corpo em seus atos isolados (no tempo, como vimos), apesar de imediato. Na conhecida seção 18 do primeiro volume de $O$ mundo como vontade e como representação Schopenhauer caracteriza o conhecimento da identidade entre vontade e corpo como sendo o conhecimento in concreto da verdade filosófica, isto é, um conhecimento não dedutível de princípios a priori, mas apenas descrito a partir da experiência concreta. A impossibilidade de se demonstrar tal identidade é o que ele caracteriza como sendo o "milagre por excelência"9. Assim, podemos induzir a partir do reconhecimento dessa identidade que: se pudéssemos conhecer tudo o que nos aparece de fora tão imediata e intimamente como conhecemos de dentro, reconheceríamos também a identidade existente entre a nossa vontade e a vontade no restante da natureza; nisso consiste o chamado "procedimento analógico"

\footnotetext{
${ }^{7}$ Cf. SCHOPENHAUER, MVR I, §18, p. 116.

${ }^{8}$ SCHOPENHAUER, MVR I, §18, p. 117.

${ }^{9}$ SCHOPENHAUER, MVR I, §18, p. 119.

Metafísica prática em Schopenhauer
} 
operado no segundo livro de $O$ mundo como vontade e como representação ${ }^{10}$, a saber, se a) reconheço a identidade da causalidade em diverentes níveis na natureza (causalidade mecânica, excitação e motivação) e b) reconheço que a ação do meu corpo é ação da minha vontade (gênese da motivação, verdade filosófica), então c) toda ação corpórea é também ação de vontade ${ }^{11}$.

Em Astronomia fisica, capítulo central de Sobre a vontade na natureza, Schopenhauer desenvolve com maior atenção o tema da identidade metafísica da vontade na natureza inorgânica, onde a vontade é considerada a partir de seu menor grau de expressão, que conhecemos pelas leis que regem a matéria, tendo naquilo que chamamos de "forças naturais" o que também em nós reconhecemos como motivo. Pensada simplesmente pela causalidade estrita (mecânica), portanto, a natureza inorgânica não parece apresentar nenhum mistério para sua compreensão, visto que nela a relação entre causa e efeito é homogênea e uniforme: a causa do movimento de um corpo, dizemos, é o movimento de outro que perde exatamente a mesma quantidade de movimento que aquele ganha, se desconsideramos o atrito. No momento em que atravessamos a fronteira entre inorgânicos e orgânicos a relação torna-se heterogênea, e o efeito se sobrepuja de tal forma à causa que esta parece praticamente nem existir para um entendimento desatento: o ato da vontade parece ser infundado e livre, também aqui como se fora "um verdadeiro milagre"

Que a todo movimento possamos atribuir uma causa e um efeito, isto é, que haja na natureza uma identidade causal, isso pode nos ser constatado exteriormente, pelo intelecto; é apenas a sua ocasião. A condição do movimento ou ação é interna, é a identidade da vontade, onde reside todo o mistério e obscuridade, em grande parte porque a relação de compreensão entre ambas é inversa, ou seja, “quanto mais próximo, portanto, um lado do mundo estiver, tanto mais perderemos o outro de vista" ${ }^{\text {13 }}$. Assim, também onde a relação de causa e efeito parece mais nitidamente compreendida, no patamar mais inferior da natureza inorgânica, a compreensão de sua identidade interior com a vontade permanece misteriosa; algo que é ainda mais latente quando nos elevamos até o fenômeno [Phänomen] da vida no reino orgânico, expresso na

\footnotetext{
${ }^{10}$ Sobre isso, ver também: BARBOZA, J. Schopenhauer: A decifração do enigma do mundo. Coleção Logos. São Paulo: Moderna, 1997.

${ }^{11} \mathrm{O}$ reconhecimento da identidade entre vontade e corpo é o que permite pensarmos a unidade (Einheit), em oposição à pluralidade (Vielheit), da vontade. SCHOPENHAUER, MVR I, p. 132. Neste momento consideramos "unidade" como expressão cósmica da "identidade", expressões intercambiáveis.

12 SCHOPENHAUER, N, p. 146.

${ }^{13}$ SCHOPENHAUER, N, p. 152.

Metafísica prática em Schopenhauer 
Revista Voluntas: Estudos sobre Schopenhauer - Vol. 6, № 1 - $1^{\circ}$ semestre de 2015 - ISSN: 2179-3786 - pp. 28-43.

desproporção magnífica entre a germinação rudimentar de uma semente e a sofisticada complexidade e diferenciação das inúmeras espécies vegetais ${ }^{14}$.

A resolução do enigma da vida e da existência deve residir, portanto, na passagem entre uma compreensão e outra, e a conexão entre o exterior e o interior que pode ser estabelecida em nosso intelecto pela reflexão dá indícios do segredo para o qual a filosofia busca solução. Estes indícios são os fenômenos da identidade metafísica da vontade, isto é, manifestações empíricas desta identidade, cuja experiência não nos é dada in abstracto, mas in concreto e que, por isso mesmo, mostrar-se-ão como mistérios para a compreensão filosófica. São estes os momentos reunidos por Schopenhauer pelo conceito de simpatia.

\section{Compaixão}

A compaixão é, para Schopenhauer, a genuína motivação moral, única capaz de combater o egoísmo natural. A origem do egoísmo, que é a motivação humana predominante, reside no conhecimento limitado e parcial da realidade, da vontade. $\mathrm{O}$ egoísmo é a resposta instantânea para a diferença: frente à multidão dos seres no mundo a vontade do indívídio se expressa enquanto "vontade de vida", manifestada no seu instinto de conservação.

O egoísmo, de acordo com sua natureza, é sem limites: o homem quer conservar incondicionalmente sua existência, a quer incondicionalmente livre da dor a qual também pertence toda penúria e privação, quer a maior soma possível de bem-estar, quer todo o gozo de que é capaz e procura, ainda, desenvolver em si outras aptidões de gozo. Tudo o que se opõe ao esforço de seu egoísmo excita sua má vontade. Quer, o quanto possível, desfrutar tudo, ter tudo. Porém, como isto é impossível, quer, pelo menos, dominar tudo. "Tudo para mim e nada para o outro" é sua palavra de ordem. O egoísmo é colossal, ele comanda o mundo. Se fosse dado pois a um indivíduo escolher entre a sua própria aniquilação e a do mundo, nem preciso dizer para onde a maioria se inclinaria ${ }^{15}$.

Submergidos ao principium individuationis do Véu de Maya ${ }^{16}$ o indivído apenas

\footnotetext{
14 "Entre a semente por vezes centenária, mesmo milenar, e a árvore, entre o solo e a seiva específica, tão altamente diferenciada, de inúmeras plantas - benéficas, venenosas, nutritivas - que um solo carrega, uma luz solar ilumina, uma chuva encharca, não há mais qualquer similaridade, e, portanto, nenhuma compreensibilidade para nós" (SCHOPENHAUER, N, p. 145).

${ }^{15}$ SCHOPENHAUER, M, p. 121.

${ }^{16}$ SCHOPENHAUER, MVR I, p. 9.

Metafísica prática em Schopenhauer 
percebe o outro com estranheza e indiferença, e, impostas as condições da vida de sofrimentos, não pode mais do que considerá-lo como um risco à sua própria existência. Diante disso, estaríamos longe de uma motivação de valor genuinamente moral, pois "a significação moral de uma ação só pode estar na sua relação com os outros"17. O interesse egoísta mostra-se, pelo contrário, como um grande inimigo, e a busca pelo fundamento último da ação humana só poderá seguir o caminho que atravesse o Véu, isto é, a diferença. A compaixão é para nós o primeiro indício concreto da identidade metafísica da vontade na medida em que é a única motivação que tem como condição o rompimento, ainda que parcial, da barreira entre o eu e o outro.

Como é possível porém que o sofrimento que não é $m e u$, que não $m e$ diz respeito, possa, no entanto, levar-me diretamente a agir, como se fosse para mim o meu próprio motivo? Como foi dito, só através do fato de que eu sinta esse sofrimento, embora me seja dado como algo externo, meramente por meio da intuição ou por notícia, que eu o sinta por simpatia, o sinta como meu e, no entanto, não em mim, mas num outro (...) Isso pressupõe, porém, que eu tenha me identificado com o outro numa certa medida e, consequentemente que a barreira entre o eu e o não-eu tenha sido, por um momento, suprimida. Só então a situação do outro, sua precisão, sua necessidade e seu sofrimento tornar-se-ão meus. Só então não o olho mais como alguém que é para mim estranho e indiferente e totalmente diferente de mim, como me é dado pela intuição empírica, mas eu sofro com ele nele, embora sua pele não encerre meus nervos ${ }^{18}$.

A partir do conhecimento de si como sujeito de vontade, para além de um mero sujeito de conhecimento, abre-se para o indivíduo uma compreensão sentida, avessa ao princípio de razão. Assim, as virtudes da justiça e da caridade (caritas, Ágape), pensadas enquanto graus de apresentação da compaixão, não são consequência da reflexão especial do intelecto, já que justamente atuam em um domínio anterior à própria racionalidade, e "assim, o mais excelente caráter pode ser encontrado até mesmo com um fraco entendimento, além disso, e a excitação de nossa compaixão não é acompanhada de qualquer esforço de nosso intelecto" ${ }^{19}$. Pelo conceito de simpatia Schopenhauer quer indicar esta experiência sentida, não refletida, de supressão do princípio de razão em direção à unidade metafísica da vontade. A compaixão revira o egoísmo e revela o sentido genuíno da máxima "o mundo sou eu" sob a forma sânscrita

\footnotetext{
${ }^{17}$ SCHOPENHAUER, M, p. 133.

${ }^{18}$ SCHOPENHAUER, M, p. 163.

${ }^{19}$ SCHOPENHAUER, WWV II, p. 688; MVR II, p. 332.

Metafísica prática em Schopenhauer
} 
do Tat twam asi (isto é tu) ${ }^{20}$ : se o mundo sou eu, não há mais alteridade e toda realidade é íntima; em outras palavras, todo o sofrimento é também meu. O instinto de conservação como expressão da vontade de vida agora não se direciona mais apenas ao indivíduo, mas amplia-se para o mundo. O "mistério da ética"21 reside no limite do discurso teórico em apanhar por via de conceitos abstratos esta identidade da vida, e a falta de uma explicação para a ação compassiva por parte do agente de modo algum deslegitima a sua existência e tampouco a sua eficácia. "Desse modo, o coração se sente dilatado; enquanto no egoísmo, contraído"22.

Toda boa ação totalmente pura, toda ajuda verdadeiramente desinteressada, que, como tal, tem exclusivamente por motivo a necessidade de outrem é, quando pesquisada até o seu último fundamento, uma ação misteriosa, uma mística prática, contanto que surja por fim do mesmo conhecimento que constitui a essência de toda mística propriamente dita e não possa ser explicável com verdade de nenhuma outra maneira. Pois o fato de que alguém dê apenas uma esmola sem com isto visar, mesmo do modo mais longínquo, outra coisa que não seja amenizar a carência que impressiona o outro só é possível contanto que ele saiba que é ele mesmo que lhe aparece agora naquela triste forma, portanto que ele reconheça sua própria essência em si no fenômeno [Erscheinung] alheio $^{23}$.

\section{Amor sexual}

O amor sexual (Geschlechtsliebe) é a maior expressão da vontade de vida no indivíduo, entendida como impulso criador, tendo o corpo (Leib) como sua objetidade e os genitais como seu foco. O desejo sexual será compreendido por Schopenhauer como gênese da manutenção da vida na espécie, a despeito da sofisticação e nobreza com que este tema é conduzido por poda poesia e literatura. Ainda que esta visão pareça demasiadamente simplista e fria em comparação com as "bolhas de sabão suprasensíveis" de sentimentos extremados - nas descrições de "Werther", "Romeu e Julieta", por exemplo - ela consiste, todavia, numa descrição que eleva o tema do amor ao seu maior nível: afinal, o que haveria de mais importante do que a constituição das gerações da espécie? ${ }^{24}$

A geração de cada indivíduo manifesta, de certo modo, uma nova Ideia platônica

\footnotetext{
${ }^{20}$ SCHOPENHAUER, WWV II, p. 688, MVR II, p. 332.

${ }^{21}$ SCHOPENHAUER, M, p. 136.

${ }^{22}$ SCHOPENHAUER, MRV I, p. 434.

${ }^{23}$ SCHOPENHAUER, M, p. 221.

${ }^{24}$ SCHOPENHAUER, WWV II, p. 612.

Metafísica prática em Schopenhauer
} 
que, neste caso, deseja por tornar-se aparente, anseia pelo seu aparecimento, a partir do seu impulso originário cego. Diferentemente do que ocorre nos demais reinos da natureza, a vontade atinge na espécie humana o seu maior grau de complexidade efetiva, de modo que aqui não somente o caráter (Ideia) de espécie é manifestado, mas também o caráter do indivíduo. A ideia de ser humano é de tal forma destacada em cada indivíduo que é como que se cada indivíduo manifestasse uma espécie distinta na natureza. E o egoísmo é manifestado com tamanha força no indivíduo que a reação natural em vistas da procriação tem de, também, seguir-se sob a roupagem de uma ação egoísta:

É verdade que a espécie tem sobre o indivíduo um direito anterior, mais rígido e maior que a efêmera individualidade: todavia, quando o indivíduo deve ser ativo e até prestar sacrifício para a conservação e o aprimoramento da espécie, a importância da questão pode não se tornar compreensível para o seu intelecto, calculado enquanto tal apenas para fins individuais, e assim possa atuar de modo conseqüente. Por conseguinte, em tal caso, a natureza só pode alcançar o seu fim se implantar no indivíduo uma certa ILUSÃO, em virtude da qual aparece como algo bom para si, o que em verdade é algo bom só para a espécie, de modo que serve a esta, enquanto presume servir a si mesmo; em todo esse processo uma efêmera quimera paira diante dele e se oferece como motivo no lugar de uma realidade. Essa ILUSÃO é o INSTINTO. Na maioria dos casos ele deve ser considerado como o sentido da ESPÉCIE, que expõe à vontade aquilo que é favorável à espécie. Mas como aqui a vontade tornou-se individual, ela tem de ser iludida de tal maneira que perceba pelo sentido do INDIVÍDUO aquilo que o sentido da espécie a ela apresenta; portanto presume seguir fins individuais, enquanto na verdade persegue meros fins gerais (esta palavra aqui tomada em sentido o mais estrito) ${ }^{25}$.

O mistério manifesta-se aqui primeiramente como tabu. Exceto quando considerado sob o nobre manto mítico de uma religião ou da transcendência a que são levados os enamorados para cima de tudo o que é terreno e de si mesmos, a procriação é assunto velado. A razão para a vergonha é também prova fática de que o impulso sexual é, no fundamento, um impulso de espécie, em que cada um carrega no interior da própria consciência a cumplicidade de um crime originário. Em verdade a culpa surge do descompasso entre os objetivos do indivíduo e da espécie, transformando a existência em um perpétuo pedágio, um investimento caro que nunca cobre os seus juros.

${ }^{25}$ SCHOPENHAUER, WWV II, p. 614.

Metafisica prática em Schopenhauer 
Este é apenas o fruto da afirmação da vontade de vida. Assim, o medo da morte, que nos ata firmemente à vida, apesar de todas as suas misérias, é realmente ilusório, mas apenas como é ilusório o impulso que nos seduz para ela. Esta tentação em si pode ser objetivamente intuída nos olhares recíprocos de desejo entre dois amantes, pois eles são a mais pura expressão da vontade de viver em sua afirmação ${ }^{26}$.

Mais importante que isto é, porém, a implicação metafísica deste amor sexual: a indestrutibilidade do nosso ser em si, para o que o nascer e o perecer é apenas ilusório. Ou seja, "a compreensão da indestrutibilidade de nosso ser coincide com a compreensão da identidade do macrocosmos com o microcosmos" ${ }^{27}$. A essa altura, nenhuma pergunta apresenta-se como tão natural quanto esta: "um tempo infinito fluiu antes do meu nascimento; o que eu era durante todo esse tempo?"28, aquela mesma expressão serve também aqui de resposta: "Isto é tu”. Enquanto vontade, o indivíduo nunca deixou de ser.

\section{Magia}

O terceiro indício simpático é desenvolvido no extenso capítulo Magnetismo animal e magia ${ }^{29}$ de Sobre a vontade na natureza. Lá, Schopenhauer encontra nas sabedorias ocultas, sobretudo no magnetismo animal $^{30}$ e nas curas simpáticas ${ }^{31}$, comprovações ainda mais profundas de sua metafísica. A escolha destas duas práticas se deve, sobretudo, por serem exemplos daquilo que já fora magia, porém adquirindo já em seu tempo uma credibilidade médica (como é o caso do magnetismo animal), mesmo que no passado já tivessem sido horrivelmente julgadas como bruxaria ou feitiçaria por séculos a fio. Mas, "para sorrir precipitadamente perante toda simpatia misteriosa ou mesmo perante qualquer efeito magico, é preciso que se considere o

${ }^{26}$ SCHOPENHAUER, WWV II, p. 651, MRV II, p. 290.

${ }^{27}$ SCHOPENHAUER, WWV II, p. 555.

28 "Eine unendliche Zeit ist vor meiner Geburt abgelaufen; was war ich alle jene Zeit hindurch?". SCHOPENHAUER, WWV II, p. 532.

${ }^{29}$ Cf. SCHOPENHAUER, N.

${ }^{30}$ Ou "mesmerismo", o magnetismo animal é atribuído a Mesmer (meados do século XVIII), e é frequentemente referido como o correspondente arcaico da hipnose. Ainda que se possa fazê-lo, preferimos neste contexto distinguí-los, caracterizando a hipnose como aquela técnica que tem por característica a indução do paciente ao sono. O termo "hipnose" só será cunhado em 1842 por James Braid.

${ }^{31}$ Nas palavras de Schopenhauer: "Um ramo da antiga magia mantém-se no povo até mesmo de modo manifesto, sendo exercitado diariamente, o que lhe foi permitido graças à sua intenção benévola, a saber: as curas simpáticas, de cuja realidade mal se pode duvidar". SCHOPENHAUER, N, p. 154. 
mundo bastante, ou mesmo absolutamente compreensível"32, e a magia mostra-se aqui como uma importante confirmação do que vinha sendo dito. Se podemos definir a magia como actio in distans (ação à distância), ou seja, ação que não ocorre por via causal determinada mas sim por via subterrânea metafísica, então devemos supor que haja um nexo metafísico em oposição ao nexo físico dos corpos; trata-se do nexo volitivo fundamental. O fenômeno sobrenatural escapa nossa compreensão causal, suspende o isolamento na ordem do indivíduo e amplia a ação da vontade que agora extrapola o seu limite corpóreo.

As primeiras experiências com o magnetismo animal são atribuídas a Franz Anton Mesmer, datadas de 1773, cuja aceitação, rica de evidências e pobre de explicações, só se dera parcialmente bastante tempo depois. Mesmer atribuía inicialmente a sua eficácia às barras magnéticas que ele segurava nas mãos, e posteriormente explicou as maravilhas do magnetismo animal de acordo com uma teoria materialista de um fluido rarefeito que a tudo penetraria, sem que com isso deixasse de agir com uma força impressionante. Outra evidência mágica é atestada pelas curas simpáticas, que popularmente chamamos simplesmente por "simpatia", aqueles procedimentos, geralmente caseiros e com o uso de materiais em um arranjo imprevisível, que visam curas às vezes cotidianas, de verrugas, febres, etc.

A razão para a resistência inclusive da chamada "magia branca" reside na falta de explicação coerente para estes fenômenos que, todavia, nunca deixaram de apresentar resultados empíricos. "O pensamento fundamental é o de que deve haver, para além da maneira regular de realizar as modificações no mundo por meio do nexo causal dos corpos, uma outra, a qual não repousaria em absoluto sobre o nexo causal"33.

Ocorre, porém, que o pressuposto aqui estabelecido era que deveria haver, além da conexão externa entre as aparições, fundamentada pelo nexum physicum [nexo físico], ainda uma outra, que atravessaria a essência em si de todas as coisas como uma espécie de conexão subterrânea, graças à qual seria possível, partindo de um ponto da aparição, agir imediatamente sobre todos os outros por meio de um nexum metaphysicum [nexo metafísico]; que, portanto, deveria ser possível agir sobre as coisas a partir de dentro, ao invés do agir comum a partir de fora, um agir da aparição sobre a aparição graças à essência em si, a qual é uma e a mesma em todas as aparições; que, assim como agimos causalmente como natura naturata [natureza naturada], nós poderíamos também ser capazes de uma ação como

\footnotetext{
${ }^{32}$ SCHOPENHAUER, N, p. 167.

${ }^{33}$ SCHOPENHAUER, N, p. 170.

Metafísica prática em Schopenhauer
} 
Revista Voluntas: Estudos sobre Schopenhauer - Vol. 6, № 1 - $1^{\circ}$ semestre de 2015 - ISSN: 2179-3786 - pp. 28-43.

$$
\text { natura naturans [natureza naturante }]^{34} \text {. }
$$

Os relatos sobre a magia, mesmo que em muitos casos consistissem em enganos, farsas e abusos, entretanto, eram paradoxalmente confirmados inclusive pela ávida caça às bruxas, que para Schopenhauer não passa de um atestado negativo para realidade destes fenômenos, cuja prescrição não seria portanto totalmente infundada. Os relatos mais sérios e explicações mais detalhadas careciam, sim, de um fundamento que, todavia, somente poderia ser encontrado em outra ordem:

Eu sou, portanto, da opinião de que a origem desse pensamento tão universal, tão inabalável, apesar da oposição de tanta experiência e do entendimento humano comum, deve ser buscada em um local muito profundo, a saber, no sentimento interno da onipotência da vontade em si, dessa vontade que é ao mesmo tempo a essência íntima do ser humano e da natureza como um todo, e na pressuposição a ele ligada de que essa onipotência poderia também alguma vez, por algum meio, ser levada a valer como partindo do indivíduo ${ }^{35}$.

O efeito da magia é pensado, assim, como resultado de uma influência completamente inexplicável entre o núcleo do corpo do magnetizador, a sua vontade, e a vontade do magnetizado. "Encontrar o caminho para tal, isto é, para suspender o isolamento em que a vontade se encontra em cada indivíduo, para uma amplificação da esfera imediata da vontade para além do corpo do querente - era essa a tarefa da magia" ${ }^{, 36}$. Isto equivale a dizer que não é a consciência do querer, a reflexão sobre o mesmo, mas o próprio querer puro que age magneticamente, ou seja, que a vontade como coisa em si é primária, e a representação secundária. Por isso, aos poucos Mesmer foi se dando conta de que não era o material utilizado - barras de ferro - a causa da cura magnética, mas a sua própria vontade, motivada pela crença, que funcionava como um tipo de tônico. Schopenhauer cita Georg Conrad Horst ${ }^{37}$ :

O poder mágico põe aquele que o possui na condição de dominar e renovar a criação, quer dizer, os reinos vegetal, animal e mineral; de modo que, se muitos agissem conjuntamente em um poder mágico, a natureza poderia ser transformada em paraíso. [...] Pois a crença submete-nos o mundo, na medida em que o acordo de nossa vontade com a divina tem como consequência que tudo, como diz Paulo, seja

\footnotetext{
${ }^{34}$ SCHOPENHAUER, N, p. 170.

${ }^{35}$ SCHOPENHAUER, N, p. 170.

${ }^{36}$ SCHOPENHAUER, N, p. 172.

${ }^{37}$ HORST, G, C. Zauberbibliothek. Vol. 1, p. 325, 119.

Metafisica prática em Schopenhauer
} 


\title{
LUAN CORRÊA DA SILVA \\ nosso e deva obedecer-nos ${ }^{38}$.
}

Isso explicaria inclusive a realidade dos milagres cristãos: Cristo tenha realizado seus milagres pelo poder da sua vontade, como quando diz a um leproso "Eu quero, sejas purificado" - um querer que para os olhos dos outros pareceria um arbítrio e que para Cristo era uma necessidade ${ }^{39}$. As divisórias que separam os indivíduos, por mais firmes que sejam, podem, portanto, permitir uma comunicação oculta, como que "por detrás dos bastidores". Na magia a vontade é onipotente, e suspende o isolamento individual da vontade.

\begin{abstract}
Ao vermos agora a vontade, a qual eu apontei como a coisa em si, o unicamente real em toda existência, o cerne da natureza, partir do individuo humano no magnetismo animal, e para alem disso perpetrar atos inexplicáveis segundo a conexão causal, quer dizer, pela lei do curso da natureza, chegando a suspender essas leis em certa medida e praticando uma efetiva actio in distans [ação a distancia], exibindo assim um domínio sobrenatural, isto é, metafisico sobre a natureza eu não saberia dizer que confirmação mais positiva de minha doutrina ainda restaria por exigir. (...) Com isso, o magnetismo animal aparece efetivamente como a metafísica prática, termo que já [Francis] Bacon de Verulâmio utilizara, em sua classificação das ciências (Instauratio magna [Instauração Magna], livro 3), para designar a magia: ela é a metafisica empírica ou experimental ${ }^{40}$.

(...)

Quiséramos, porém, estabelecer, segundo a classificação de Bacon, a magia como a metafísica prática; então seria certo que a metafísica teórica a relacionar-se corretamente com ela não poderia ser outra que não a minha decomposição do mundo em vontade e representação ${ }^{41}$.
\end{abstract}

\section{Conclusão}

Após inúmeras referências às maiores contribuições daqueles que se ocuparam do assunto, Schopenhauer conclui que o verdadeiro agente do magnetismo animal, e de toda ação mágica, é a vontade. Assim, o magnetismo animal e a magia são efetivamente como uma metafísica prática - como metafísica empírica ou experimental -, isto é, a antecipação daquilo que é desenvolvido na sua metafísica da vontade, cuja decomposição do mundo entre vontade e representação serve de melhor correlato teórico. A perseguição às bruxas não é de maneira alguma infundada, mas provém da

\footnotetext{
${ }^{38}$ HORST apud SCHOPENHAUER, N, p. 189.

${ }^{39}$ Este relato é atribuído a Jane Leade, para quem "a magia mais elevada encontra-se na vontade". LEADE apud SCHOPENHAUER, N, p. 189.

${ }^{40}$ SCHOPENHAUER, N, p. 162.

${ }^{41}$ SCHOPENHAUER, N, p. 192.

Metafisica prática em Schopenhauer 
Revista Voluntas: Estudos sobre Schopenhauer - Vol. 6, № 1 - $1^{\circ}$ semestre de 2015 - ISSN: 2179-3786 - pp. 28-43.

constatação correta da força primordial com que lidavam em suas práticas; o que o fanatismo religioso não percebia (como também a ciência do século XVIII) é resumido por Schopenhauer em uma referência de Agrippa von Nettesheim em Epistulae: "Ele não vive nos céus e tampouco nos infernos: ele habita em nós mesmos. O espírito que vive em nós executa-o por conta própria" 42.

O que está em jogo na passagem que abre este texto é a manifestação empírica da identidade metafísica da vontade, que reúne três fenômenos aparentemente muito distintos e desconexos. É o momento em que uma verdade fundamental torna-se para nós um mistério vivo, uma experiência concreta. É por isso que a física, em seu sentido mais antigo grego de "physis", deve chegar, em todas as suas ramificações, a um ponto final onde as suas explicações já não avançam mais, e este ponto é a sua fronteira com a metafísica. Haverá sempre, por detrás das aparências, algo de inexplicável. E mesmo onde a relação causal for mais evidente, como no choque entre dois corpos, ainda assim permanecerá o mistério da "possibilidade da passagem do movimento", que é incorpóreo. A incompreensibilidade do sentido mais oculto da natureza, como vontade, não se restringe, portanto, apenas aos fenômenos sobrenaturais; mais do que isso, qualquer tentativa de explicação metafísica configura-se, antes, como uma explicação sobrenatural: metafísico e sobrenatural são aqui, portanto, sinônimos. A atração magnética da gravidade, o choque mecânico, a eletricidade, a fecundação, o embrião, o amor sexual e a compaixão não são mais do que a magia entendida em seu sentido mais originário.

\section{Referências bibliográficas}

SCHOPENHAUER, A. Arthur Schopenhauers handschriftlicher Nachlaß. Philosophische Vorlesungen - Metaphysik der Natur. In: SCHOPENHAUER, A. Arthur Schopenhauers sämtliche Werke, vol X; hrsg. Von Paul Deussen. Munique: R. Piper, 1913, p. 143.

R. Piper, 1942.

. Arthur Schopenhauers Sämtliche Werke. Hrsg. Von Paul Deussen. Munique:

. Metafisica do Amor/ Metafísica da Morte (Sobre a morte e sua relação com a indestrutibilidade de nosso ser em si). Trad. de Jair Barboza. São Paulo: Martins Fontes, 2001.

O mundo como vontade e como representação. Tomo I. Tradução, 
apresentação, notas e índices de Jair Barboza. 2a ed. São Paulo: UNESP, 2015.

. O mundo como vontade e representação. Tomo II: Complementos. Trad.

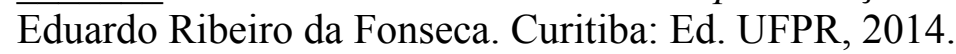

. Sobre o fundamento da moral. Trad. Maria Lúcia Cacciola. $2^{\mathrm{a}}$ ed. São Paulo: Martins Fontes, 2001.

. Sobre a vontade na natureza. Tradução, prefácio e notas de Gabriel Valladão Silva. Porto Alegre: L\&PM, 2013.

Hedra, 2012.

. Sobre a Ética. Organização e tradução Flamarion C. Ramos. São Paulo:

BARBOZA, J. Schopenhauer: a decifração do enigma do mundo. Coleção Logos. São Paulo: Moderna, 1997.

. Schopenhauer: 'die Erscheinung', 'das Phänomen'. Revista Voluntas: Estudos sobre Schopenhauer, vol. 5, $\mathrm{n}^{\mathrm{o}}$ 1, pp. 03-08. Disponível em: http://www.revistavoluntas.com.br/uploads/1/8/1/8/18183055/v5-n1-1-2014-art1-barboza_jair.pdf . Acesso em 15 Jul. 2015.

HORST, G, C. Zauberbibliothek. Vol. 1, p. 325, 119.

SILVA, L. C. Sobre a vontade na natureza (Resenha). Tradução, prefácio e notas de Gabriel Valladão Silva. Porto Alegre: L\&PM, 2013, 236 p. Revista Voluntas, 2014. Disponível em: http://www.revistavoluntas.com.br/uploads/1/8/1/8/18183055/v4-n2-2-2013-res01luan_correa_da_silva.pdf. Acesso em 15 Jul. 2015. 